\title{
Magnetism and superconductivity in $3 d$-metal-substituted Bi-based cuprates having the 2:2:0:1 structure
}

\author{
K. Remschnig, J. M. Tarascon, P. F. Miceli, and G. W. Hull \\ Bell Communications Research, Red Bank, New Jersey 07701 \\ W. R. McKinnon \\ National Research Council of Canada, Ottawa, Canada \\ (Received 16 July 1990)
}

\begin{abstract}
The effects of the substitution for $\mathrm{Cu}$ or $\mathrm{Mn}$ by either a magnetic (Ni) or a nonmagnetic ( $\mathrm{Zn}$ ) $3 d$ metal on the physical properties of the superconducting compounds $\mathrm{Bi}_{1.2} \mathrm{~Pb}_{0.8} \mathrm{La}_{0.5} \mathrm{Sr}_{1.5} \mathrm{CuO}_{6+y}$ and of the antiferromagnetic insulating phases $\mathrm{Bi}_{2} \mathrm{Sr}_{2} \mathrm{MnO}_{6+y}$ and $\mathrm{BiPbSr}_{2} \mathrm{MnO}_{6}$, all isostructural to the 10-K superconducting $\mathrm{Bi}_{2} \mathrm{Sr}_{2} \mathrm{CuO}_{z}$ (2:2:0:1) phase, have been investigated with use of $\mathrm{x}$-ray powder diffraction, susceptibility, and resistivity measurements. We found that both $\mathrm{Ni}$ and $\mathrm{Zn}$ substitute for $\mathrm{Cu}$ and $\mathrm{Mn}$ with a range of solubility strongly dependent upon the nature of both the dopant and the host compound. For instance, in the Cu-based compounds the range of solubility is only a few percent $(5 \%$ for $\mathrm{Ni}$ and $2 \%$ for $\mathrm{Zn}$ ) whereas in the $\mathrm{Mn}$-based compounds the range of solubility can be extended up to $20 \%$ for $\mathrm{Zn}$ or $30 \%$ for $\mathrm{Ni}$. In the superconducting $\mathrm{Bi}_{1.2} \mathrm{~Pb}_{0.8} \mathrm{La}_{0.5} \mathrm{Sr}_{1.5} \mathrm{Cu}_{1-x} M_{x} \mathrm{O}_{6+y}$ system, both $\mathrm{Ni}$ and $\mathrm{Zn}$ depress the $T_{c}$ at approximately the same rate $(8 \mathrm{~K} / \mathrm{mol} \%)$, so that the magnetism of the dopant has no effect on the $T_{c}$ as observed for the other high- $T_{c}$ cuprates. The Mn-based materials order antiferromagnetically and we found that upon substitution by $\mathrm{Ni}$ and $\mathrm{Zn}$ the antiferromagnetic transition temperature $T_{N}$ decreases less dramatically for the magnetic $\mathrm{Ni}[5 \mathrm{~K} /(10$ at. \%)] than for the nonmagnetic $\mathrm{Zn}[30 \mathrm{~K} /(10$ at. \% $)]$. A consideration of the exchange interactions can account for these results.
\end{abstract}

\section{INTRODUCTION}

In the studies of high- $T_{c}$ oxides, doping experiments have established general phenomenological trends that have enhanced the basic understanding of their physical properties. $^{1,2}$ Excessive cationic and anionic substitutions have been carried out in the La-based $\left(\mathrm{La}_{2} \mathrm{CuO}_{4}\right)$ (Refs. 3-6) and $\mathrm{Y}$-based $\left(\mathrm{YBa}_{2} \mathrm{Cu}_{3} \mathrm{O}_{4}\right)$ (Refs. 7-10) compounds as well as for the $\mathrm{Nd}-\mathrm{Ce}-\mathrm{Cu}-\mathrm{O}$ system. ${ }^{11,12}$ In contrast, only limited substitutional data are available for the Bi-based layered compounds. ${ }^{13,14}$

For the La- and Y-based compounds solid solutions on the $\mathrm{Cu}$ site exist over a broad range of composition for various $3 d$ metals $(\mathrm{Ni}, \mathrm{Zn}, \mathrm{Fe}, \mathrm{Co}, \ldots)$. In contrast, in the Bi-based compounds of general formula $\mathrm{Bi}_{2} \mathrm{Sr}_{2} \mathrm{Ca}_{n-1} \mathrm{Cu}_{n} \mathrm{O}_{z}$ the substitution for $\mathrm{Cu}$ by divalent ions $\mathrm{Ni}$ or $\mathrm{Zn}$ is limited to a few atomic percent $(<2 \%)$, whereas the substitution by trivalent ions ( $\mathrm{Fe}, \mathrm{Co}$, and $\mathrm{Mn}$ ) can be complete. ${ }^{15-17}$ However, a main difference between the $\mathrm{Bi}$-based compounds and the other cuprates is the presence of a structural modulation that originates in the $\mathrm{Bi}-\mathrm{O}$ layers and that is associated with extra oxygens inserted in these layers. To determine whether this structural difference is the origin of the limited $\mathrm{Ni}$ or $\mathrm{Zn}$ substitution in these phases we decided to investigate the substitution for $\mathrm{Cu}$ or $\mathrm{Mn}$ by $\mathrm{Ni}$ and $\mathrm{Zn}$ in both modulated $\left(\mathrm{Bi}_{2} \mathrm{Sr}_{1.5} \mathrm{La}_{0.5} \mathrm{CuO}_{z}\right.$ and $\left.\mathrm{Bi}_{2} \mathrm{Sr}_{2} \mathrm{MnO}_{z}\right)$ and nonmodulated $\left(\mathrm{Bi}_{1.2} \mathrm{~Pb}_{0.8} \mathrm{Sr}_{1.5} \mathrm{La}_{0.5} \mathrm{CuO}_{6}\right.$ and $\left.\mathrm{BiPbSr}_{2} \mathrm{MnO}_{6}\right)$ host materials [note that to obtain modulation-free material of the $\mathrm{Cu}$-based compound the substitution of $\mathrm{Bi}$ by $\mathrm{Pb}$ must be accompanied by a partial substitution of Sr by La (Ref. 20)].

For all high- $T_{c}$ oxides it was found that substitution on the $\mathrm{Cu}$ site strongly depresses the $T_{c}$. Contrary to the well-established experimental and theoretical fact that within the low-temperature superconductors the presence of magnetic impurities depresses the $T_{c}$ much stronger than that of nonmagnetic impurities, ${ }^{18}$ it was found that for La-based and Y-based compounds the magnetism of the dopant has no effect on the $T_{c}$. This behavior is associated with a much shorter correlation length in these materials (10-30 $\AA$ ). When compared to the BCS-type materials ( $>300 \AA$ ), this leads to the conclusion that local disorder rather than magnetism is the important factor for the suppression of superconductivity in these materials. It has been shown, that the $\mathrm{Nd}-\mathrm{Ce}-\mathrm{Cu}-\mathrm{O}$ compound, possessing a correlation length slightly larger $(90$ A) than the other high- $T_{c}$ cuprates, exhibits a behavior close to an ideal BCS system with respect to magnetic impurities. ${ }^{19}$ The $T_{c}$ 's of the La-Sr-Cu-O and Nd-Ce-Cu-O systems are quite different $(25 \mathrm{~K}$ for the $\mathrm{Nd}$-based system instead of $40 \mathrm{~K}$ for the La-based system). A more convincing comparison will require a material with a similar $T_{c}$. The superconducting $n=1 \mathrm{Bi}$-based phase whose $T_{c}$ can be increased to $25 \mathrm{~K}$ (similar to the Nd-based system) upon doping provides a unique opportunity to reexamine the doping effect on two materials with nearly identical $T_{c}$ 's. Thus, we decided to investigate the superconducting behavior of the Bi-layered compounds upon $\mathrm{Ni}$ and $\mathrm{Zn}$ substitution. We found that although the host $\mathrm{Bi}$ - 
based layer material has the same $T_{c}$ as the Nd-based system, its behavior with respect to $\mathrm{Ni}$ and $\mathrm{Zn}$ substitution resembles that of the high- $T_{c}$ oxides and not of the $\mathrm{Nd}$ based system.

Like the superconducting properties, the magnetism of the cuprates has been studied for possible links to superconductivity. Many of the high- $T_{c}$ cuprates that have been found have related compounds that are antiferromagnetic insulators. For instance, replacing $\mathrm{Cu}$ by $\mathrm{Mn}$ in the $2: 2: 0: 1$ phase leads to the antiferromagnetic insulator $\mathrm{Bi}_{2} \mathrm{Sr}_{2} \mathrm{MnO}_{y}$ that orders at $T_{N}=150 \mathrm{~K} .{ }^{17,22}$ Similarly for the superconducting properties, one would expect the magnetic properties of the antiferromagnetic insulating phases to be affected by any structural distortions, as well as by any modification of the magnetically active $3 d$ metal $\mathrm{MO}_{2}$ layer. Thus, we studied how the substitution for $\mathrm{Mn}$ by $\mathrm{Ni}$ and $\mathrm{Zn}$ affects the $T_{N}$ in the parent compound $\mathrm{Bi}_{2} \mathrm{Sr}_{2} \mathrm{MnO}_{y}$, hoping that by studying the magnetism in these related compounds one will gain a better understanding of the cuprates.

\section{EXPERIMENTAI}

For different series of samples,

$$
\begin{aligned}
& \mathrm{Bi}_{2} \mathrm{Sr}_{1.5} \mathrm{La}_{0.5} \mathrm{Cu}_{1-x} M_{x} \mathrm{O}_{6+y}, \\
& \mathrm{Bi}_{1.2} \mathrm{~Pb}_{0.8} \mathrm{Sr}_{1.5} \mathrm{La}_{0.5} \mathrm{Cu}_{1-x} M_{x} \mathrm{O}_{6}, \\
& \mathrm{Bi}_{2} \mathrm{Sr}_{2} \mathrm{Mn}_{1-x} M_{x} \mathrm{O}_{6+y},
\end{aligned}
$$

and

$$
\mathrm{BiPbSr}_{2} \mathrm{Mn}_{1-x} M_{x} \mathrm{O}_{6}
$$

denoted $A, B, C$, and $D$, respectively, with $M=\mathrm{Ni}, \mathrm{Zn}$ and $x$ ranging from 0 to 1 , have been prepared by mixing stoichiometric amounts of the corresponding oxides or carbonates $\left(\mathrm{Bi}_{2} \mathrm{O}_{3}, \mathrm{PbO}, \mathrm{SrCO}_{3}, \mathrm{La}_{2} \mathrm{O}_{3}, \mathrm{CuO}, \mathrm{MnO}_{2}\right.$, $\mathrm{ZnO}$, and $\mathrm{NiO}$ ) all $99.999 \%$ pure.

Samples of the series $A$ and $B$ were calcined at $800^{\circ} \mathrm{C}$ in air for $24 \mathrm{~h}$, then reground in an agate mortar, heated up to $900^{\circ} \mathrm{C}$, and held there for $24 \mathrm{~h}$. To achieve better homogeneity, this step was repeated several times with the samples being pressed to pellets and reground between each step. The resulting samples were annealed under a stream of flowing oxygen for $48 \mathrm{~h}$ and quenched in air to room temperature. For the $B$ series only, a part of each sample was additionally annealed at $900^{\circ} \mathrm{C}$ under flowing $\mathrm{O}_{2}$ for three more days and quenched in liquid nitrogen.

The $C$ and $D$ series were prepared similarly as $A$ and $B$ but with a reducing ambient $\left(\mathrm{N}_{2}\right)$ instead of an oxidizing ambient $\left(\mathrm{O}_{2}\right)$. (The Bi-based manganese phases are not stable under an oxygen ambient for temperatures greater than $600^{\circ} \mathrm{C}$.) The samples were heated up slowly $(40 \mathrm{~h})$ up to $970^{\circ} \mathrm{C}$, held there for $48 \mathrm{~h}$, and cooled slowly. To improve the homogeneity of the samples, this step was repeated several times again but the heating period was shortened to $3 \mathrm{~h}$ on subsequent heatings.

X-ray powder diffraction (using a SCINTAG-PADV diffractometer with $\mathrm{Cu} K \alpha$ radiation) was performed for the characterization of all samples. Lattice parameters were calculated from $x$-ray-diffraction data using a least- squares method. The solubility ranges determined by $\mathrm{x}$ rays reported below are defined by the dopant composition $x$ of the first sample that shows weak extra Bragg peaks in the diffraction patterns. The presence of weak extra peaks associated with the structural modulation has made the determination of the solubility range in some samples less accurate. To monitor possible changes in the oxygen content TGA (thermogravimetric analysis) measurements in a reducing atmosphere $\left(5 \% \mathrm{H}_{2}\right.$ in $\left.\mathrm{Ar}\right)$ were carried out for several samples by monitoring the weight loss of the material when heated on a sapphire substrate at a rate of $10^{\circ} \mathrm{C} / \mathrm{min}$ from 50 to $900^{\circ} \mathrm{C}$.

The superconducting properties were determined using both standard four-probe resistivity and ac-susceptibility measurement techniques. Meissner fractions as well as the magnetic properties of the antiferromagnetic samples [series $(C)$ and $(D)$ ], were measured with a superconducting quantum interference device (SQUID) magnetometer (SHE-Corp).

\section{RESULTS}

\section{A. Cu-based compounds}

The x-ray diffraction patterns of the $\mathrm{Ni}$ - and $\mathrm{Zn}$-doped $\mathrm{Bi}_{2} \mathrm{La}_{0.5} \mathrm{Sr}_{1.5} \mathrm{Cu}_{1-x} M_{x} \mathrm{O}_{y}$ samples with $x<0.075$ were fully indexed on the basis of the orthorhombic unit cell reported in the literature. The very few weak extra lines remaining in the powder-diffraction spectra were related to the presence of an incommensurate modulation along the a axis in this compound. The occurrence of impurity lines in the $x$-ray-diffraction patterns of $\mathrm{Bi}_{2} \mathrm{La}_{0.5} \mathrm{Sr}_{1.5} \mathrm{Cu}_{1-x} M_{x} \mathrm{O}_{6+y} \quad(M=\mathrm{Ni}, \mathrm{Zn})$ for samples with $x>0.075$ suggests that the range of solubility is less than $10 \%$ for both elements.

Figure 1(a) shows the variation of the lattice parameters for the $\mathrm{Ni}$ - and $\mathrm{Zn}$-doped $\mathrm{Bi}_{2} \mathrm{La}_{0.5} \mathrm{Sr}_{1.5} \mathrm{Cu}_{1-x} M_{x} \mathrm{O}_{y}$ series. An increase in the lattice parameter $a$ and $b$ with increasing $x$ for both $\mathrm{Ni}$ - and $\mathrm{Zn}$-doped samples and a slight decrease in the lattice parameter $c$ can be observed. Because of the small difference between the ionic radii of the dopant with respect to the substituend (the ionic radius of $\mathrm{Ni}^{2+}=0.69 \AA$ and the ionic radius of $\mathrm{Zn}^{2+}=0.74$ $\AA$ versus $0.73 \AA$ for the ionic radius of $\mathrm{Cu}^{2+}$ ) these changes in lattice parameters are somewhat surprising. This behavior may result from a different distortion of the transition-metal-oxygen octahedra due to the different Jahn-Teller effect of the $3 d$ metals. $\mathrm{Zn}^{2+}$, a $d^{10}$ ion, has no Jahn-Teller effect in contrast to a $d^{9}$ ion such as $\mathrm{Cu}^{2+}$. A Jahn-Teller distortion causes an elongation along the $c$ axis of the oxygen octahedron surrounding the $3 d$ metal, resulting in an increase of the $c / a$ ratio. Thus as $\mathrm{Cu}^{2+}$ ions are replaced by $\mathrm{Zn}^{2+}$ ions one would expect the Jahn-Teller distortion to be reduced, leading to a decrease of the $c / a$ ratio as observed experimentally [increase of $(a+b) / 2$ and slight decrease in the lattice parameter $c$ ]. Like $\mathrm{Zn}^{2+}, \mathrm{Ni}^{2+}$ should affect the structure in a similar way, consistent with the same trends in the lattice-parameter changes observed for both $\mathrm{Ni}$ - and Zn-doped samples.

However, changes of the unit-cell volume can also be related to changes in the oxygen content accompanying 

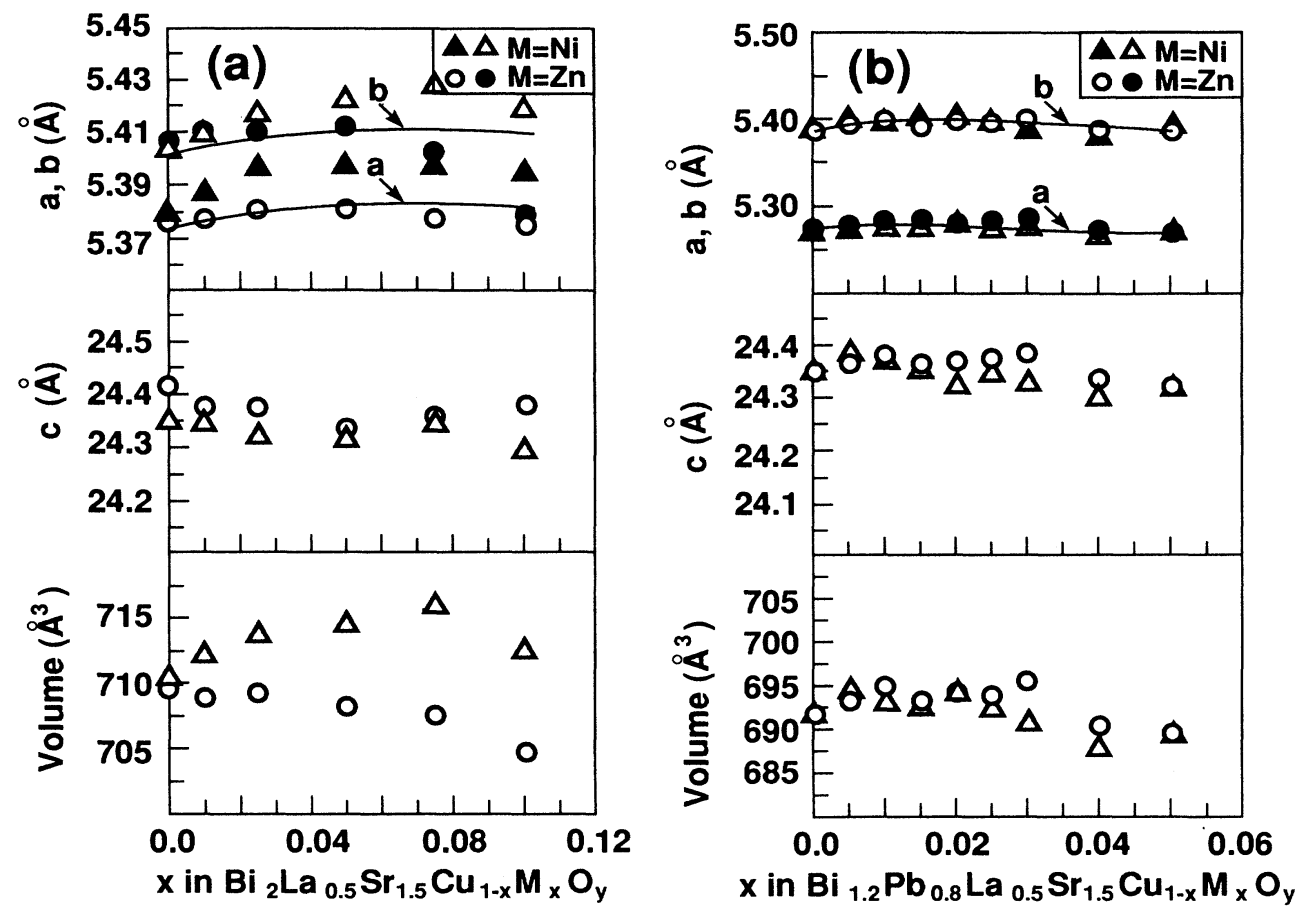

FIG. 1. Unit-cell parameters $\left(a, b, c\right.$, and $V$ ) as a function of dopant content $x$ in (a) $\mathrm{Bi}_{2} \mathrm{La}_{0.5} \mathrm{Sr}_{1.5} \mathrm{Cu}_{1-x} M_{x} \mathrm{O}_{6+y}$ and (b) $\mathrm{Bi}_{1.2} \mathrm{~Pb}_{0.8} \mathrm{La}_{0.5} \mathrm{Sr}_{1.5} \mathrm{Cu}_{1-x} M_{x} \mathrm{O}_{6}$ for $M=\mathrm{Ni}$ (triangles) and $M=\mathrm{Zn}$ (circles).

the $\mathrm{Zn}$ and Ni substitutions. To test this possibility TGA measurements in an reducing atmosphere $(5 \% \mathrm{H}$ in $\mathrm{Ar}$ ) were performed. No noticeable difference in weight loss could be detected within the limit of resolution of the method (better than 0.05 oxygen per formula unit). Thus, we rule out that the observed changes in the lattice constants can be related to a change in the oxygen content.

We now present the crystallographic data for the Niand $\mathrm{Zn}$-doped $\mathrm{Bi}_{1.2} \mathrm{~Pb}_{0.8} \mathrm{La}_{0.5} \mathrm{Sr}_{1.5} \mathrm{Cu}_{1-x} M_{x} \mathrm{O}_{6}$ systems (series $B$ ) in which $\mathrm{Bi}$ has been partially replaced by $\mathrm{Pb}$. In this series it is much easier to determine the exact limit of solubility, since these materials do not show a structural modulation. Furthermore, the influence of substitution on the superconducting properties can also be used to determine this limit, as we will show later.

X-ray-diffraction patterns of the $\mathrm{Bi}_{1.2} \mathrm{~Pb}_{0.8} \mathrm{La}_{0.5} \mathrm{Sr}_{1.5} \mathrm{Cu}_{1-x} M_{x} \mathrm{O}_{6}$ series could also be fully indexed based on the orthorhombic distorted subcell of $\mathrm{Bi}_{2} \mathrm{Sr}_{2} \mathrm{CuO}_{6+y}$, with a difference-that no modulation occurs in these compounds as shown by TEM (transmission electron microscopy) studies. $^{20}$ Figure 1(b) shows the variation of the orthorhombic lattice parameters. Note that the substitution for $\mathrm{Bi}$ by $\mathrm{Pb}$ enhances the orhorhombic distortion so that $\Delta(b-a)=0.09 \AA$ instead of $0.03 \AA$ for the nonsubstituted $\mathrm{Pb}$ sample. The range of solubility for $\mathrm{Ni}$ and $\mathrm{Zn}$ in $\mathrm{Bi}_{1.2} \mathrm{~Pb}_{0.8} \mathrm{La}_{0.5} \mathrm{Sr}_{1.5} \mathrm{Cu}_{1-x} M_{x} \mathrm{O}_{6}$ is smaller by a factor of about 2 than for $\mathrm{Bi}_{2} \mathrm{La}_{0.5} \mathrm{Sr}_{1.5} \mathrm{Cu}_{1-x} M_{x} \mathrm{O}_{y}$ since the samples with $x>0.05$ for $\mathrm{Ni}$ and with $x>0.04$ for $\mathrm{Zn}$ are definitely multiphase. Nevertheless, in spite of the smaller solubility range the lattice-parameter changes for both
$\mathrm{Ni}$ and $\mathrm{Zn}$ substitution reveal the same trends as before with a slight increase in $a$ and $b$. As in the case of the $A$-series, TGA measurements show no noticeable changes in the oxygen content due to the substitution. The oxygen content is also found to be independent of the heating treatment (ambient and cooling rate).

Figure 2 shows the variation of the superconducting critical temperatures (as determined by ac-susceptibility measurements by defining the width of the transition, which was in the order of $1 \mathrm{~K}$ for all samples, as $\Delta T$ between $10 \%$ and $90 \%$ amplitude of the signal) as a function of the dopant context $x$. Both $\mathrm{Ni}$ and $\mathrm{Zn}$ substitution depress the $T_{c}$ at approximately the same rate $(8$ $\mathrm{K} / \mathrm{mol} \%$ ) at low $x$. While there is a linear relation for $T_{c}$ versus $x$ in $\mathrm{Bi}_{1.2} \mathrm{~Pb}_{0.8} \mathrm{La}_{0.5} \mathrm{Sr}_{1.5} \mathrm{Cu}_{1-x} \mathrm{Ni}_{x} \mathrm{O}_{6}$ across the whole range until the $T_{c}$ is below $4.2 \mathrm{~K}$, the $T_{c}$ remains more or less the same for all $x>0.015$ in $\mathrm{Bi}_{1.2} \mathrm{~Pb}_{0.8} \mathrm{La}_{0.5} \mathrm{Sr}_{1.5} \mathrm{Cu}_{1-x} \mathrm{Zn}_{x} \mathrm{O}_{6}$ (see Fig. 2). This behavior indicates that the solubility range is limited to 0.02 for $\mathrm{Zn}$ in contrast to the value 0.05 for $\mathrm{Ni}$, which is slightly below the limit determined from $x$-ray-diffraction data. Resistivity measurements for several members of the $\mathrm{Zn}$ or Ni-doped series are displayed in Fig. 3. Only the samples that show metallic behavior are superconducting; if not, they are semiconducting, indicating the absence of the metallic state between the superconducting and semiconducting state, in agreement with previous studies of the $3 d$-metal-substituted $\mathrm{La}_{1.85} \mathrm{Sr}_{0.15} \mathrm{CuO}_{4-y}$ and $\mathrm{YBa}_{2} \mathrm{Cu}_{3} \mathrm{O}_{7-y}$ systems. ${ }^{4,10,21}$ It is interesting to note that none of the $\mathrm{Zn}$ - or Ni-doped $\mathrm{Bi}_{1.2} \mathrm{~Pb}_{0.8} \mathrm{La}_{0.5} \mathrm{Sr}_{1.5} \mathrm{Cu}_{1-x} M_{x} \mathrm{O}_{y}$ superconducting samples 


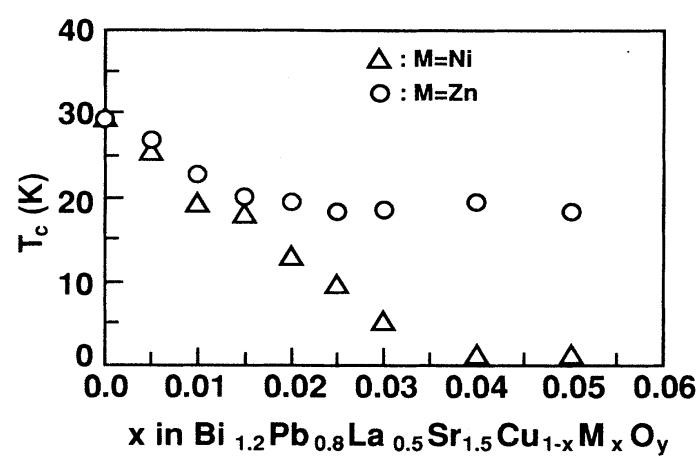

FIG. 2. Superconducting transition temperatures $T_{c}$ (as derived by ac susceptibility) for $\mathrm{Bi}_{1.2} \mathrm{~Pb}_{0.8} \mathrm{La}_{0.5} \mathrm{Sr}_{1.5} \mathrm{Cu}_{1-x} M_{x} \mathrm{O}_{6}$ $(M=\mathrm{Ni}, \mathrm{Zn})$ as a function of dopant content $x$.

shows a semiconductinglike behavior above the $T_{c}$ (usually indicative of inhomogeneities or multiphases), whereas this was quite common for the $\mathrm{Y}$ - or La-based systems. It is doubtful that samples of these systems containing six components are more homogeneous than those of the $\mathrm{Y}$ and La-based systems. The difference more likely arises from the presence of small amounts of secondary phases which are metallic for the Bi-based system and semiconducting for the Y-and La-based systems.

Measurements of the Meissner effect show that there is no significant change in the Meissner fraction for both the $\mathrm{Ni}$ - and $\mathrm{Zn}$-doped series. However, the signal obtained by Meissner measurements broadens at higher sub-

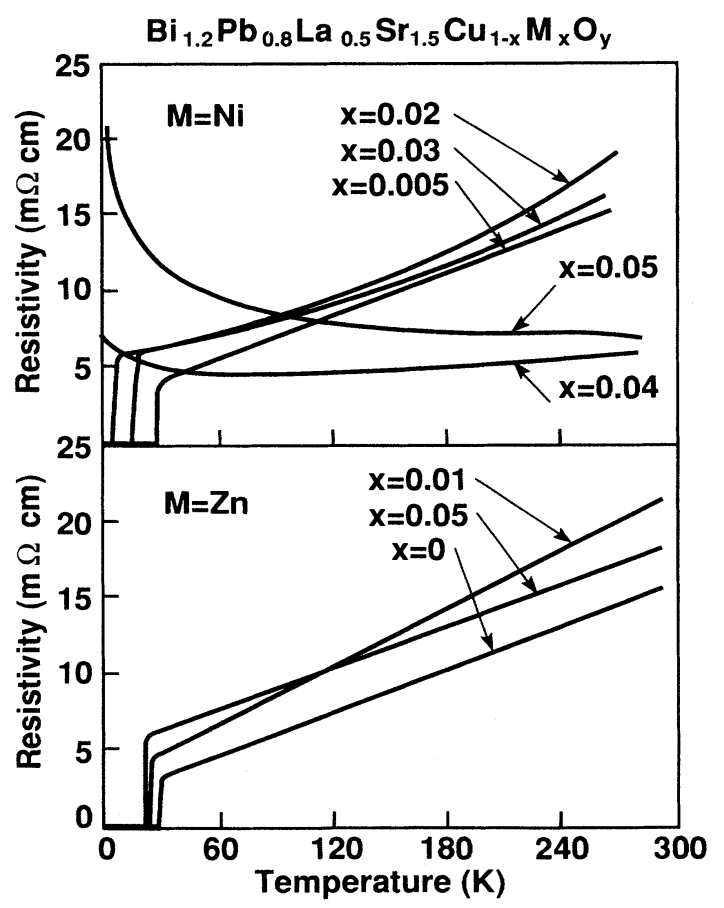

FIG. 3. The temperature dependence of the resistivity for some selected samples of the $\mathrm{Bi}_{1.2} \mathrm{~Pb}_{0.8} \mathrm{La}_{0.5} \mathrm{Sr}_{1.5} \mathrm{Cu}_{1-x} M_{x} \mathrm{O}_{6+y}$ series with $M=\mathrm{Ni}$ (top) and $M=\mathrm{Zn}$ (bottom). stitution levels. This is in contrast to the ac-susceptibility and the resistivity measurements, which both show very sharp transitions for the whole range in the $\mathrm{Ni}$ - as well as the $\mathrm{Zn}$-doped series. Critical-field measurements were performed on an undoped sample of $\mathrm{Bi}_{1.2} \mathrm{~Pb}_{0.8} \mathrm{Sr}_{1.5} \mathrm{La}_{0.5} \mathrm{CuO}_{6}$ having a $T_{c}$ of $29 \mathrm{~K}$ and a $\Delta T_{c}$ of $1 \mathrm{~K}$. Upon increasing the applied field by steps of 0.5 $\mathrm{T}$ up to $5 \mathrm{~T}$ we note a broadening of the superconducting transition, but only a small shift (no greater than $1 \mathrm{~K}$ ) of the superconducting transition. These data indicate that these materials have a high critical field, corresponding to a short coherence length, as observed for the other high$T_{c}$ oxides, with the exception of the Nd-based cuprates.

\section{B. Mn-based compounds}

We now present results of our studies when $\mathrm{Mn}$ is replaced by $\mathrm{Ni}$ and $\mathrm{Zn}$ in the Mn-based compounds $\mathrm{Bi}_{2} \mathrm{Sr}_{2} \mathrm{Mn}_{1-x} M_{x} \mathrm{O}_{6+y} \quad(C$ series $)$ and $\mathrm{BiPbSr}_{2} \mathrm{Mn}_{1-x} M_{x} \mathrm{O}_{6}$ ( $D$ series). It is important to remind the readers, that both the $C$ and $D$ series of compounds show crystal structures similar to the $A$ and $B$ series, respectively, with the presence of the structural modulation that is present for the compounds without $\mathrm{Pb}$ and which disappears for the compounds containing $\mathrm{Pb}$. Previous studies have shown that in the modulated $\mathrm{Bi}_{2} \mathrm{Sr}_{2} \mathrm{MnO}_{y}$ phases $\mathrm{Mn}$ can exist in various oxidation states $(+2,+3$, and +4$),{ }^{22,23}$ whereas $\mathrm{Mn}$ adopts only the oxidation state +3 in the $\mathrm{Pb}$-containing $\mathrm{BiPbSr}_{2} \mathrm{MnO}_{6}$ samples. ${ }^{24,25}$

$X$-ray powder-diffraction spectra collected for samples of the $C$ and $D$-series $\mathrm{Ni}$ - or $\mathrm{Zn}$-doped manganese-based series could be indexed on the basis of the orthorhombic structures given in the literature. ${ }^{16}$ Good agreement between calculated and observed intensities was achieved for both the modulated and nonmodulated structures. The variation of the lattice parameters are shown in Fig. 4. Ni-doped $\mathrm{Bi}_{2} \mathrm{Sr}_{2} \mathrm{Mn}_{1-x} M_{x} \mathrm{O}_{y}$ and $\mathrm{BiPbSr}_{2} \mathrm{Mn}_{1-x_{x}} M_{x} \mathrm{O}_{y}$ samples were definitely single phase up to $x=0.3$ and showed the presence of only a few very weak impurities in the diffraction patterns for $x=0.4$ and 0.5 . In contrast, for the $\mathrm{Zn}$-doped series weak impurity lines were observed already for $x=0.3$, indicating as observed previously for the $\mathrm{Cu}$-based compounds that the solubility range is smaller for the $\mathrm{Zn}$ doped than for Ni-doped samples. A striking difference, however, with the $\mathrm{Cu}$-based compounds is that the solubility range for $\mathrm{Ni}$ or $\mathrm{Zn}$ in the $\mathrm{Mn}$-based compounds is larger by a factor 10 .

We present the crystallographic data [Fig. 4(b)] for the $\mathrm{BiPbSr}_{2} \mathrm{MnO}_{6}$ series that is structurally modulation free and contains only $\mathrm{Mn}^{3+}$. The orthorhombic distortion characterized by the splitting between the lattice parameters $a$ and $b$ remains constant through the range of solubility. But, the lattice parameters $a$ and $b$ increase upon increasing both the $\mathrm{Ni}$ and $\mathrm{Zn}$ doping in contrast to the lattice parameter $c$ that decreases for both series with a faster decrease for the $\mathrm{Ni}$-doped than for the $\mathrm{Zn}$-doped samples. The observation that the lattice parameters $a, b$, and $c$ are constant for $x>0.2$ in $\mathrm{BiPbSr}_{2} \mathrm{Mn}_{1-x} \mathrm{Zn}_{x} \mathrm{O}_{6}$ and $x>0.3$ in $\mathrm{BiPbSr}_{2} \mathrm{Mn}_{1-x} \mathrm{Ni}_{x} \mathrm{O}_{6}$ suggests, like the oc- 

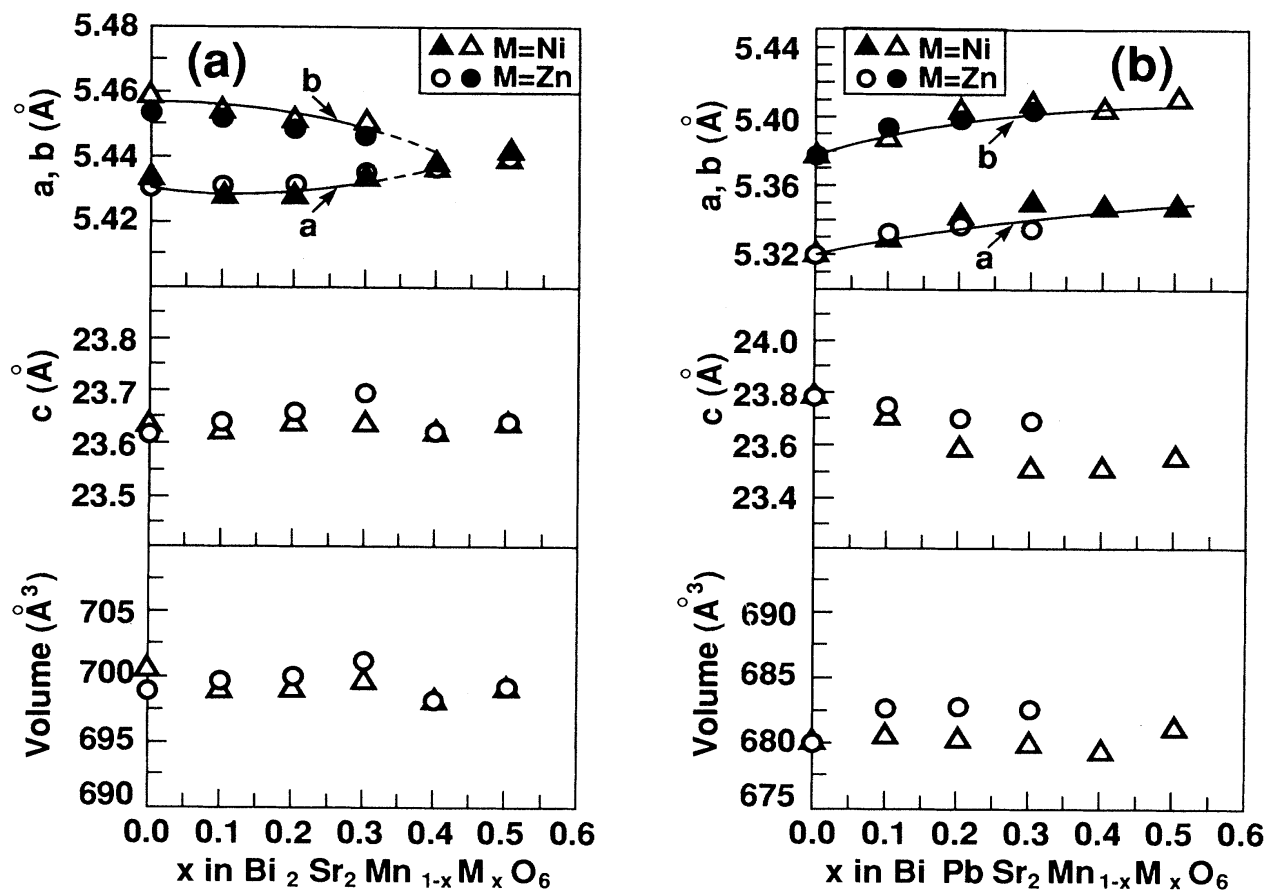

FIG. 4. Unit-cell parameters $\left(a, b, c\right.$, and $V$ ) as a function of dopant content $x$ in (a) $\mathrm{Bi}_{2} \mathrm{Sr}_{2} \mathrm{Mn}_{1-x} M_{x} \mathrm{O}_{6+y}$ and (b) $\mathrm{BiPbSr}_{2} \mathrm{Mn}_{1-x} M_{x} \mathrm{O}_{6}$ with $M=\mathrm{Ni}$ (triangles) and $M=\mathrm{Zn}$ (circles). Note that in the case of (a) the lattice constant $a$ corresponds to that of the subcell ( $=a / 4$ of the whole cell).

currence of the impurity lines in the $x$-ray-diffraction spectra, that the solubility range is limited to 0.2 for $\mathrm{Zn}$ and 0.3 for $\mathrm{Ni}$.

The lattice parameter $a$ represents the distance between two $\mathrm{Mn}$ atoms within the $\mathrm{MnO}_{2}$ planes. Thus, by replacing $\mathrm{Mn}^{3+}$ in the high-spin state $(r=0.65 \AA$ ) by a larger ion such as $\mathrm{Ni}^{2+}$ of atomic radius $0.69 \AA$ or $\mathrm{Zn}^{2+}$ of atomic radius $0.74 \AA$, one would expect an increase in the lattice parameter $a$ as observed experimentally. The $3 d$ metal is located at the center of an oxygen octahedron and an increase in the basal-plane distance $a$ results in a compression of the octahedron along the $c$ axis (i.e., a decrease of the lattice parameter $c$ ) consistent with our $\mathrm{x}$ ray data. The $\mathrm{Ni}$ and $\mathrm{Zn}$ substitution involves the replacement of a trivalent ion $\left(\mathrm{Mn}^{3+}\right)$ by a divalent ion $\left(\mathrm{Ni}^{2+}\right.$ or $\left.\mathrm{Zn}^{2+}\right)$. Thus, to maintain charge balance the oxygen content should decrease with increasing substitution. TGA measurements performed on several $\mathrm{Ni}$ - and Zn-doped samples (which fail to give accurate absolute values but can detect relative changes) have revealed a significant trend: a decrease of the oxygen content occurs with increasing substitution concentration for both $\mathrm{Ni}$ and $\mathrm{Zn}$, as expected from simple valence considerations.

We turn to the crystallographic data for the $\mathrm{Ni}$ - and $\mathrm{Zn}$-doped $\mathrm{Bi}_{2} \mathrm{Sr}_{2} \mathrm{MnO}_{z}$ series whose structure contains four different crystallographic $\mathrm{Mn}$ sites with $\mathrm{Mn}$ in various oxidation states. Figure 4(a) shows the variation of the lattice parameters for this series. Upon $\mathrm{Ni}$ or $\mathrm{Zn}$ substitution in the $\mathrm{Bi}_{2} \mathrm{Sr}_{2} \mathrm{MnO}_{z}$ phase the lattice parameters $a$ and $b$ progressively converge so that the orthorhombic distortion appears to be quite small around $x=0.4$. At the same composition the samples were also found to become multiphase. Finally, Fig. 4(a) shows that upon $\mathrm{Zn}$ or Ni substitution the unit-cell volume and lattice parameter $c$ slightly increase in contrast with the c-axis compressions observed for the $\mathrm{BiPbSr}_{2} \mathrm{MnO}_{6}$ series. In the $\mathrm{Pb}$-doped compounds the divalent $\mathrm{Ni}$ and $\mathrm{Zn}$ ions substituted for the only existing trivalent $\mathrm{Mn}$ ions whereas for the samples without $\mathrm{Pb}$ they can substitute for $\mathrm{Mn}^{2+}, \mathrm{Mn}^{3+}$, and $\mathrm{Mn}^{4+}$. From size considerations both $\mathrm{Ni}^{2+}(r=0.69 \AA)$ and $\mathrm{Zn}^{2+}(r=0.74 \AA)$ are expected to replace $\mathrm{Mn}^{3+}(r=0.65 \AA)$ rather than $\mathrm{Mn}^{2+}$ $(r=0.83 \AA)$ or $\mathrm{Mn}^{4+}(r=0.53 \AA)$ (these values are for $3 d$ metals in their high-spin configuration). From valence considerations, one would expect that divalent $\mathrm{Ni}$ and $\mathrm{Zn}$ ions substitute for the divalent $\mathrm{Mn}^{2+}$ ions. In this case, because of the large size of $\mathrm{Mn}^{2+}$ compared with $\mathrm{Ni}^{2+}$ or $\mathrm{Zn}^{2+}$ one would expect a decrease of the lattice parameter $a$ resulting in an elongation of the octahedron along the c axis (i.e., an increase in the lattice parameter $c$ ). Slight decreases in the average $a$ - and $b$-lattice-parameter changes $[(a+b) / 2]$ and the slight increase in the lattice parameter $c$ measured upon $\mathrm{Ni}$ or $\mathrm{Zn}$ substitution seem to favor the substitution for $\mathrm{Mn}^{2+}$ by $\mathrm{Ni}^{2+}$ or $\mathrm{Zn}^{2+}$. If both divalent $\mathrm{Zn}$ and $\mathrm{Ni}$ replace $\mathrm{Mn}^{3+}$, as initially assumed, the oxygen content of $\mathrm{Bi}_{2} \mathrm{Sr}_{2} \mathrm{Mn}_{1-x} M_{x} \mathrm{O}_{y}$ has to change, in order to maintain charge balance, whereas it will remain constant if $\mathrm{Zn}$ and $\mathrm{Ni}$ replace $\mathrm{Mn}^{2+}$. No noticeable changes in the oxygen content with increasing $\mathrm{Ni}$ or $\mathrm{Zn}$ substitution could be determined by TGA. That, together with the fact that we could not observe any change in the modulation, seems to favor the substitution 
of $\mathrm{Zn}$ or $\mathrm{Ni}$ for $\mathrm{Mn}^{2+}$. Future neutron experiments will be necessary in order to resolve this point conclusively.

\section{MAGNETISM}

We have shown that the modulated $\mathrm{Bi}_{2} \mathrm{Sr}_{2} \mathrm{MnO}_{y}$ phase orders antiferromagnetically at $120 \mathrm{~K}$. At this temperature, there is a sharp rise in the susceptibility (due to a weak ferrimagnetism induced by the structural modulation), ${ }^{17,22}$ whereas the nonmodulated $\mathrm{BiPbSr}_{2} \mathrm{MnO}_{6}$ phase orders antiferromagnetically at higher temperatures $\left(T_{N}\right.$ between 150 and $190 \mathrm{~K}$ ) with a less-pronounced peak in the susceptibility consistent with the absence of the structural modulation. ${ }^{24,25}$ Both compounds are twodimensional (2D) antiferromagnetic insulators, where the separation between the $\mathrm{MnO}_{2}$ layers is large.

We have measured how the $T_{N}$ changes upon $\mathrm{Ni}$ or $\mathrm{Zn}$ doping in the $C$ and $D$ series. Figure 5 displays the variation of the susceptibility as a function of the temperature for several members of the $\mathrm{BiPbSr}_{2} \mathrm{Mn}_{1-x} M_{x} \mathrm{O}_{6}$ series. The measurements were taken at a field of $3 \mathrm{kG}$ on warming and cooling after the samples have been cooled to $4.2 \mathrm{~K}$ in zero field. For both Ni- and $\mathrm{Zn}$-doped samples [Figs. 5(a) and 5(b), respectively] the susceptibility cusp corresponding to the 3D antiferromagnetic ordering shifts towards low temperatures upon increasing dopant content with a decrease faster for $\mathrm{Zn}\left[d T_{N}=30 \mathrm{~K} /(10\right.$ at. \% $\mathrm{Zn})]$ than for $\mathrm{Ni}\left[d T_{N}=5-8 \mathrm{~K} /(10\right.$ at. $\left.\% \mathrm{Ni})\right]$. This phenomena can be explained in several ways: $\mathrm{Re}$ placing a $\mathrm{Mn}^{3+}$ ion with spin $S=2$ by a $\mathrm{Ni}^{2+}$ ion with spin $S=1$ decreases the exchange interactions and thereby the $3 d$ antiferromagnetic ordering $T_{N}$ (which depends on the spin $S$ ). The replacement of $\mathrm{Mn}$ by a nonmagnetic ion (with spin $S=0$ ) such as $\mathrm{Zn}$ is expected to weaken even more the intralayer coupling than the substitution by $\mathrm{Ni}$, thereby leading to a stronger decrease in $T_{N}$ for increasing dopant content for the $\mathrm{Zn}$ - than for the $\mathrm{Ni}$ doped series as observed experimentally. On the other hand, the decrease in $T_{N}$ can also be related simply to the fact that in both $\mathrm{Zn}$ and $\mathrm{Ni}$ substitution the $2 \mathrm{D}$ correlation in the planes is disrupted by the substituent, which results in a decrease of the $3 \mathrm{D}$ ordering temperature $T_{N}$. In the case of the dopant $\mathrm{Zn}$ the effect of disorder on suppressing the transition temperature $T_{N}$ has to be much stronger, because of the lack of any magnetic superexchange. In the case of the dopant $\mathrm{Ni}$, which allows superexchange, the disorder may result mainly from the fact that contrary to $\mathrm{Mn}$ where spins are always aligned perpendicular to the plane, the spins can also be aligned in the plane as known from the $\mathrm{La}_{2} \mathrm{NiO}_{4}$ case.

For these materials which are $2 \mathrm{D}$ in nature, we should also observe a broad maximum in the susceptibility at temperatures much larger than $T_{N}$. For instance, in $\mathrm{La}_{2} \mathrm{CuO}_{4}$, which has a $T_{N}$ of about $200 \mathrm{~K}$, the $2 \mathrm{D}$ ordering was deduced from the broad maximum in the temperature dependence of the susceptibility which occurs below $1000 \mathrm{~K}$. The susceptibility of the undoped sample (Fig. 5) decreases slightly from room temperature to go through a minimum just before $T_{N}$. The increase of the susceptibility with increasing temperature up to $300 \mathrm{~K}$ may suggest that the $2 \mathrm{D}$ correlation develops at relatively

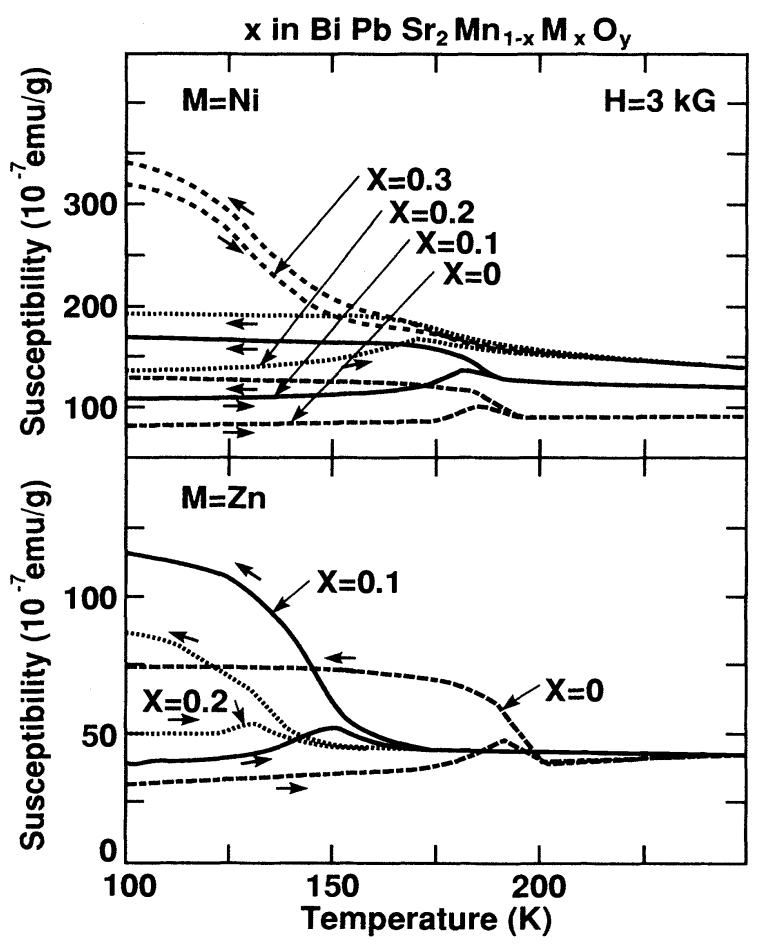

FIG. 5. Temperature dependence of the magnetic susceptibility for several members of the $\mathrm{BiPbSr}_{2} \mathrm{Mn}_{1-x} M_{x} \mathrm{O}_{6}$ series with $M=\mathrm{Ni}$ (top) and $M=\mathrm{Zn}$ (bottom). The applied magnetic field was $3 \mathrm{kG}$.

low temperatures. With increasing either $\mathrm{Ni}$ - or $\mathrm{Zn}$ dopant content in these materials this feature is completely overwhelmed and replaced by an increase in the susceptibility with decreasing temperature, suggesting either that it has been shifted to higher temperatures (which would be inconsistent with the observed decrease in $T_{N}$ ), or that by introducing disorder within the magnetic $\mathrm{MO}_{2}$ sheets the $2 \mathrm{D}$ correlations have been suppressed.

Figure 6 shows the variation of susceptibility as a func-

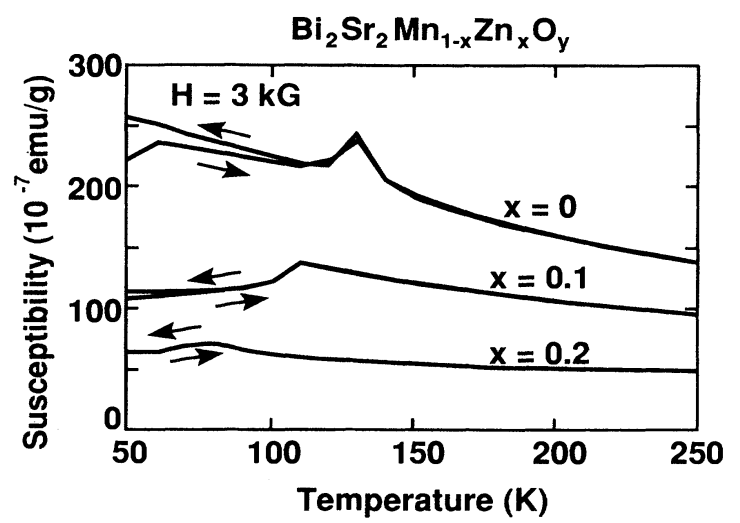

FIG. 6. The temperature dependence of the magnetic susceptibility as a function of dopant content $x$ is shown for several members of the $\mathrm{Bi}_{2} \mathrm{Sr}_{2} \mathrm{Mn}_{1-x} \mathrm{Zn}_{x} \mathrm{O}_{6+y}$ series. 


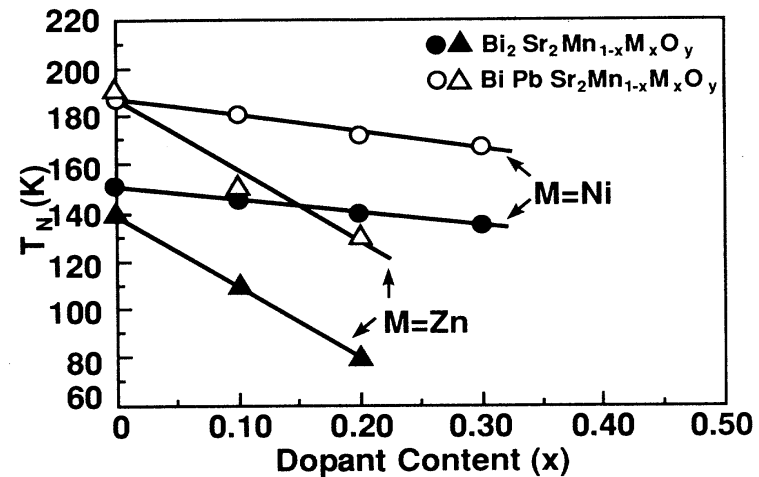

FIG. 7. The antiferromagnetic ordering temperature $T_{N}$ is plotted as a function of dopant content $x$ for both the $\mathrm{Bi}_{2} \mathrm{Sr}_{2} \mathrm{Mn}_{1-x} M_{x} \mathrm{O}_{6+y}$ and $\mathrm{BiPbSr}_{2} \mathrm{Mn}_{1-x} M_{x} \mathrm{O}_{6}$ series with $M=\mathrm{Ni}$ and $\mathrm{Zn}$.

tion of the temperature for the $\mathrm{Zn}$-doped $\mathrm{Bi}_{2} \mathrm{Sr}_{2} \mathrm{MnO}_{z}$ series. As before, $T_{N}$ decreases with increasing $\mathrm{Zn}$ dopant content. A main difference-which may result from the fact that the structure is modulated-however, is the absence of a minimum in the susceptibility just before the 3D ordering temperature. The variation in $T_{N}$ upon $\mathrm{Ni}$ substitution for the same sample is plotted in Fig. 7. Note that the rate at which $T_{N}$ decreases is faster when $\mathrm{Mn}$ is replaced by $\mathrm{Zn}$ than by $\mathrm{Ni}$ as observed for the Mn-based samples containing $\mathrm{Pb}$.

\section{DISCUSSION}

Substitution by either a magnetic $\left(\mathrm{Ni}^{2+}\right)$ or a nonmagnetic $\left(\mathrm{Zn}^{2+}\right)$ transition metal in various $\mathrm{Bi}$-based layered oxides (Fig. 8) has yielded several interesting observations: (1) The range of solubility of $\mathrm{Ni}$ and $\mathrm{Zh}$ dopants in the $\mathrm{Cu}$-based compounds $\mathrm{Bi}_{2} \mathrm{La}_{0.5} \mathrm{Sr}_{1.5} \mathrm{Cu}_{1-x} M_{x} \mathrm{O}_{y}$ and $\mathrm{Bi}_{1.2} \mathrm{~Pb}_{0.8} \mathrm{La}_{0.5} \mathrm{Sr}_{1.5} \mathrm{Cu}_{1-x} M_{x} \mathrm{O}_{y}$ is significantly lower (about 3-8 times) than in the Mn-based insulating compounds $\mathrm{Bi}_{2} \mathrm{Sr}_{2} \mathrm{Mn}_{1-x} M_{x} \mathrm{O}_{y}$ and $\mathrm{BiPbSr}_{2} \mathrm{Mn}_{1-x} M_{x} \mathrm{O}_{y}$ $(M=\mathrm{Ni}, \mathrm{Zn})$. (2) Within the $\mathrm{Cu}$ - or $\mathrm{Mn}$-based compounds, the range of solubility for $\mathrm{Zn}$ is always significantly lower than that for $\mathrm{Ni}$. (3) The range of solubility for $\mathrm{Ni}$ or $\mathrm{Zn}$ is independent of whether or not

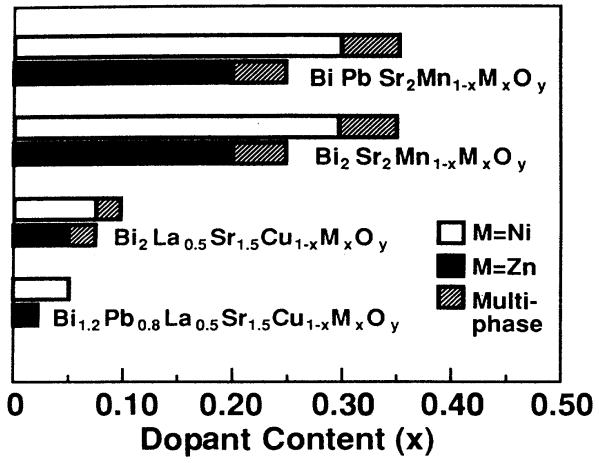

FIG. 8. Range of solubility for $\mathrm{Ni}$ and $\mathrm{Zn}$ in various $\mathrm{Bi}$-based layered compounds with the 2:2:0:1 structure. the host material has a modulated or nonmodulated structure, all of which leads us to conclude that the range of solubility of the $3 d$ metals not only depends on the nature of the dopant, but also on the nature of the transition metal they have to replace with the main result that electronic rather than structural effects govern the limit of solubility.

The smaller amount of the $\mathrm{Zn}$ dopant compared with the Ni dopant that can be substituted for the $3 d$ metal in the structures might be limited by the stability of the expanding unit-cell volume beyond a certain limit, consistent with the fact that $\mathrm{Zn}^{2+}$ is larger than $\mathrm{Cu}^{2+}, \mathrm{Ni}^{2+}$, and $\mathrm{Mn}^{3+}$. However, a more likely possibility is that these solubility limits are established by the thermodynamics of the competing phases, so that at different formation temperatures the solubility ranges might be different for $\mathrm{Ni}$ and $\mathrm{Zn}$. We have carried out experiments in this direction and found that the range of temperature over which these compounds form is very narrow (less than $100^{\circ} \mathrm{C}$ ), thus limiting any conclusions that can be made with respect to the change in solubility as a function of the annealing temperature.

The large difference in $\mathrm{Ni}$ or $\mathrm{Zn}$ solubility between the $\mathrm{Cu}$ - and Mn-based compounds, however, cannot be explained only in terms of the difference in ionic radii. A major relevant difference between the $\mathrm{Cu}$ - and $\mathrm{Mn}$-based compounds lies in their different oxidation-reduction behavior (i.e., in their ability to change their valence) in oxide compounds. Whereas oxide compounds having Mn ions in oxidation states $2+, 3+$, and $4+$ are quite common, compounds in which the oxidation state of $\mathrm{Cu}$ is $3+$ are rare and most, like $\mathrm{LaCuO}_{3}$ or $\mathrm{La}_{2} \mathrm{Cu}_{0.5} \mathrm{Li}_{0.5} \mathrm{O}_{4}$ must be synthesized under high pressure. In $\mathrm{Bi}_{2} \mathrm{La}_{0.5} \mathrm{Sr}_{1.5} \mathrm{CuO}_{y}$ or $\mathrm{Bi}_{1.2} \mathrm{~Pb}_{0.8} \mathrm{La}_{0.5} \mathrm{Sr}_{0.5} \mathrm{CuO}_{6}$ the for$\mathrm{mal}$ valence of $\mathrm{Cu}$ is, as reported elsewhere, 2.23 (Ref. 20). When a divalent ion is substituted for $\mathrm{Cu}$ in these materials, so as to maintain charge balance, the remaining $\mathrm{Cu}$ ions have to be oxidized (i.e., the $\mathrm{Cu}$ valence has to increase) or the oxygen content has to decrease. Studies of the $\mathrm{Bi}_{1.2} \mathrm{~Pb}_{0.8} \mathrm{La}_{0.5} \mathrm{Sr}_{1.5} \mathrm{CuO}_{6}$ phase have shown that this compound cannot exist for oxygen stoichiometries lower than 6 , leaving the oxidation state of $\mathrm{Cu}$ as the only possibility to compensate for the charge unbalance created by the Ni or $\mathrm{Zn}$ substitution. Thus, it is the difficulty in oxidizing $\mathrm{Cu}$ that limits the solubility range of $\mathrm{Ni}$ or $\mathrm{Zn}$ in these materials. In contrast, for the Mn-based materials, $\mathrm{Mn}$ can easily be oxidized to $\mathrm{Mn}^{3+}$ or $\mathrm{Mn}^{4+}$. Therefore the solubility range for $\mathrm{Ni}$ or $\mathrm{Zn}$ is expected to be larger, as observed experimentally.

The finding that doping with both $\mathrm{Zn}$ and $\mathrm{Ni}$ suppresses the $T_{c}$ in the $25-\mathrm{K} \mathrm{Bi}_{1.2} \mathrm{~Pb}_{0.8} \mathrm{La}_{0.5} \mathrm{Sr}_{1.5} \mathrm{CuO}_{6}$ phase at approximately the same rate $(8 \mathrm{~K} /$ at. $\%)$ with no difference between magnetic and nonmagnetic ions, leads to the conclusion that this system behaves similarly to the $\mathrm{Y}-\mathrm{Ba}-\mathrm{Cu}-\mathrm{O}$ or $\mathrm{La}-\mathrm{Sr}-\mathrm{Cu}-\mathrm{O}$ systems. Thus, in the $25-\mathrm{K}$ $\mathrm{Bi}$-based cuprates, as for $\mathrm{Y}-\mathrm{Ba}-\mathrm{Cu}-\mathrm{O}$ or $\mathrm{La}-\mathrm{Sr}-\mathrm{Cu}-\mathrm{O}$, disorder plays a major role in depressing the $T_{c}$. It is interesting to recall that for the $25-\mathrm{K} \mathrm{Nd}-\mathrm{Ce}-\mathrm{Cu}-\mathrm{O}$ cuprate (a chemical system identical to the Bi-based phase) magnetic impurities have been found to depress the $T_{c}$ faster than nonmagnetic impurities as in conventional super- 
conductors. We should emphasize that in spite of belonging to the same chemical system (cuprates) and having the same $T_{c}$ these materials have a quite different coherence length, as suggested by critical-field measurements $\left[d T_{c} / d H=1 \mathrm{~K} /(5 \mathrm{~T})\right.$ for $\mathrm{Bi}_{1.2} \mathrm{~Pb}_{0.8} \mathrm{La}_{0.5} \mathrm{Sr}_{1.5} \mathrm{CuO}_{6}$ and 20 $\mathrm{K} /(5 \mathrm{~T})$ for $\left.\mathrm{Nd}_{1.85} \mathrm{Ce}_{0.15} \mathrm{CuO}_{4}\right]$. Determining the origin of such a difference could be an important step in understanding the pairing mechanism in the high- $T_{c}$ oxides.

Finally with respect to the antiferromagnetic ordering in the $\mathrm{Bi}_{2} \mathrm{Sr}_{2} \mathrm{MnO}_{y}$ and $\mathrm{BiPbSr}_{2} \mathrm{MnO}_{y}$ compounds that is yet not fully understood, we show (Fig. 7) (1) that substitution for $\mathrm{Mn}$ by $\mathrm{Ni}$ suppresses the $T_{N}$ more slowly than the substitution by $\mathrm{Zn}$ and (2) that within the same dopant the depression of $T_{N}$ is independent of whether the structure of the host compound is modulated or not. As expected, the influence of the nonmagnetic $3 d^{10}$ ele- ments $\mathrm{Zn}^{2+}$ with spin $S=0$ is much more drastic than that of the magnetic $3 d^{8} \mathrm{Ni}^{2+}$ (with spin $S=1$ ). We believe that it is the decrease in the magnetic spin of the substituted ion combined with the disorder introduced by the substitution, which leads to a shortening of the inplane $2 \mathrm{D}$ correlation length, thereby shifting the 3D antiferromagnetic ordering temperature to lower temperatures.

\section{ACKNOWLEDGMENTS}

K. Remschnig is grateful to the Fonds zur Förderung der Wissenshaftlichen Forschung for support (Project: J $0460 \mathrm{CHE}$ ). Furthermore the authors want to thank J. H. Wernick, B. Bagley, and L. Greene for helpful comments and discussions.
${ }^{1}$ L. H. Greene and B. G. Bagley, in Physical Properties of High Temperature Supercondutors II, edited by D. M. Ginsberg (World Scientific, Singapore, 1990).

${ }^{2}$ J. M. Tarascon and B. G. Bagley, in Chemistry of Superconducting Materials, edited by T. Vanderah (Noyes, Park Ridge, NJ, 1990).

${ }^{3}$ K. Remschnig, P. Rogl, E. Gratz, H. Müller, and P. Fischer, Physica C 158, 458 (1989).

${ }^{4}$ G. Hilscher, N. Pillmayr, R. Eibler, E. Bauer, K. Remschnig, and P. Rogel, Z. Phys. B 72, 461 (1988).

${ }^{5}$ J. M. Tarascon, L. H. Greene, P. Barboux, W. R. McKinnon, G. W. Hull, T. P. Orlando, K. A. Delin, S. Foner, and E. J. McNiff, Phys. Rev. B 36, 8393 (1987).

${ }^{6}$ G. Xiao, A. Bakhshai, M. Z. Cieplak, Z. Tesanovic, and C. L. Chien, Phys. Rev. B 39, 315 (1989).

${ }^{7}$ K. Remschnig, P. Rogl, R. Eibler, G. Hilscher, N. Pillmayr, H. Kirchmayr, and E. Bauer, Physica C 153-155, 906 (1988).

${ }^{8}$ L. H. Greene, J. M. Tarascon, B. G. Bagley, P. Barboux, W. R. McKinnon, and G. W. Hull, Rev. Solid State Sci. 1, 199 (1987).

${ }^{9}$ G. Xiao, H. Streitz, A. Gavrin, Y. W. Du, and C. L. Chien, Phys. Rev. B 35, 8782 (1987).

${ }^{10}$ J. M. Tarascon, P. Barboux, P. F. Miceli, L. H. Greene, G. W. Hull, M. Eibschutz, and S. A. Sunshine, Phys. Rev. B 37, 7458 (1988).

${ }^{11}$ E. Wang, J. M. Tarascon, L. H. Greene, G. W. Hull, and W. R. McKinnon, Phys. Rev. B 41, 6582 (1990).

${ }^{12}$ G. Hilscher, S. Pöllinger, M. Forsthuber, N. Pillmayr, K. Remschnig, P. Rogl, M. Reissner, W. Steiner, and P. Knoll, Physica C 167, 472 (1990).

${ }^{13}$ S. Yamagata, K. Adachi, M. Onoda, H. Fujishita, M. Sera, Y. Ando, and M. Sato, Solid State Commun. 74, 177 (1990).

${ }^{14}$ P. Kulkarni, S. K. Kulkarni, A. S. Nigavekar, S. K. Agarwal, V. P. S. Awana, and A. V. Narlikar, Physica C 166, 530
(1990).

${ }^{15}$ J. M. Tarascon, P. F. Miceli, P. F. Barboux, D. M. Hwang, G. W. Hull, M. Giroud, L. H. Greene, Y. LePage, W. R. McKinnon, E. Tselepsis, G. Pleizier, M. Eibschutz, D. A. Neumann, and J. J. Rhyne, Phys. Rev. B 39, 11589 (1989).

${ }^{16}$ J. M. Tarascon, Y. LePage, and W. R. McKinnon, Eur. J. Solid State Inorg. Chem. T27, 81 (1990).

${ }^{17}$ W. R. McKinnon, E. Tselepis, Y. LePage, S. P. McAllister, G. Pleizier, J. M. Tarascon, P. F. Miceli, R. Ramesh, G. W. Hull, J. V. Waszcak, J. J. Rhyne, and D. A. Neumann, Phys. Rev. B 41, 4489 (1990).

${ }^{18}$ A. A. Abrikosov and L. P. Gorkov, Zh. Eksp. Teor. Fiz. 39, 1781 (1960) [Sov. Phys. JETP 12, 1243 (1961)].

${ }^{19}$ J. M. Tarascon, E. Wang, S. Kivelson, B. G. Bagley, G. W. Hull, and R. Ramesh, Phys. Rev. B 42, 218 (1990).

${ }^{20}$ J. M. Tarascon, W. R. McKinnon, Y. LePage, K. Remschnig, R. Ramesh, R. Jones, G. Pleizier, and G. W. Hull, Physica C 172, 13 (1990).

${ }^{21}$ K. Remschnig, P. Rogl, E. Bauer, R. Eibler, G. Hilscher, H. Kirchmayr, and N. Pillmayr, in High- $T_{c}$ Superconductors, Proceedings of International Discussion Meeting on High- $T_{c}$ Superconductors, Mauterndorf, Austria, 1988, edited by $\mathbf{H}$. Weber (Plenum, New York, 1989).

${ }^{22}$ W. R. McKinnon, E. Tselepis, J. M. Tarascon, P. F. Miceli, K. Remschnig, G. W. Hull, D. A. Neumann, and J. J. Rhyne, Phys. Rev. B 43, 5468 (1991).

${ }^{23}$ P. F. Miceli, J. M. Tarascon, G. W. Hull, E. Tselepis, Y. LePage, W. R. McKinnon, S. P. McAllister, G. Pleizier, J. J. Rhyne, and D. A. Neumann, Bull. Am. Phys. Soc. 35, 249 (1990).

${ }^{24}$ J. M. Tarascon, Y. LePage, W. R. McKinnon, R. Ramesh, M. Eibschutz, E. Tselepsis, E. Wang, and G. W. Hull, Physica C 167, 20 (1990).

${ }^{25}$ P. F. Miceli (private communication). 